\title{
Solución inmediata a una crisis. Mujeres nicaragüenses que asumen el trabajo de los cuidados en Costa Rica
}

Recibido: 6 de agosto 2020 Revisado: 25 de noviembre 2020 Aprobado: 16 de diciembre de 2020

Ana Lucía Fernández Fernández Costarricense. Tiene el Doctorado con énfasis en Sociología otorgado por la Universidad Libre de Berlín,

Alemania. Actualmente, es

investigadora del Instituto de Estudios de Género de la

Universidad Estatal a Distancia,

San José, Costa Rica. Ella ha

trabajado en proyectos para la incorporación de la perspectiva de género en instancias de educación superior. En los últimos años ha estudiado la feminización de la migración en Costa Rica, el trabajo no remunerado y de los cuidados en Costa Rica, los estudios de uso del tiempo y las familias transnacionales. Además, es especialista en perspectivas feministas decoloniales e interseccionales. Correo electrónico: anfernandez@uned.ac.cr

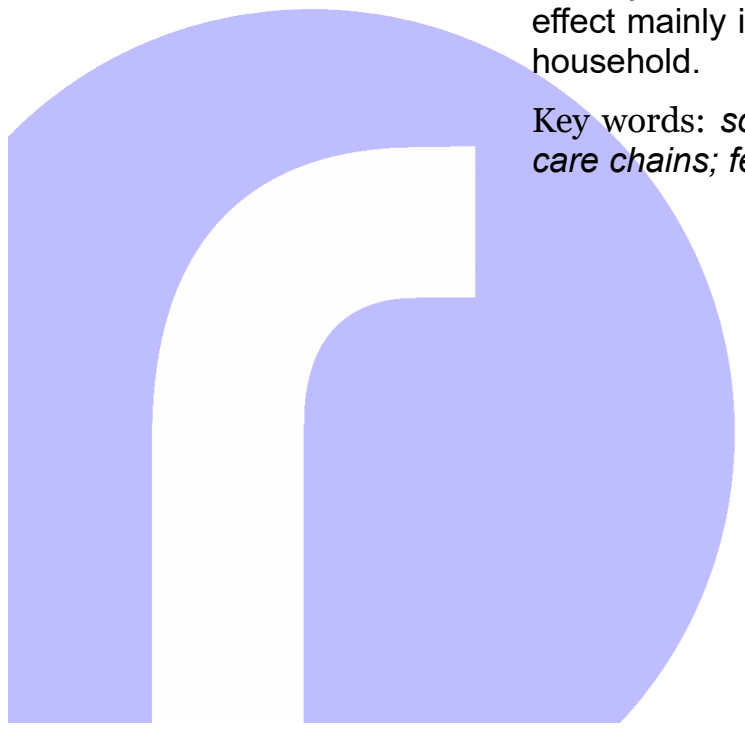

https://revistas.uned.ac.cr/index.php/rupturas c) (1) (2) household.
Resumen: En este artículo se exponen algunos de los datos del capítulo de contexto sociodemográfico de la tesis doctoral titulada «La colonialidad del ser en las prácticas performativas de mujeres migrantes, trabajadoras y jefas de hogar para el sostenimiento de la vida de sus propias familias. Una investigación en San José, Costa Rica». Se centra en analizar las condiciones de la organización social de los cuidados en Costa Rica y explica la crisis generada por la falta de corresponsabilidad social en los cuidados, situación que genera tensiones a lo interno de los hogares y que ha afectado, sobre todo, a las mujeres, en general; y a las mujeres migrantes jefas de hogar nicaragüenses, en particular.

Palabras clave: organización social de los cuidados; trabajo doméstico y de los cuidados; cadenas globales de cuidados; feminización de la migración; jefas de hogar

\section{Prompt Solution to a Crisis. Nicaraguan Women Assuming the Carework in Costa Rica}

Abstract: This paper exposes part of the data developed in the chapter related to sociodemographic context, in the doctoral "The coloniality of being in the performative practices of migrant women, workers, and heads of household for the support of the lives of their own families. A research in San Jose, Costa Rica. This article shows data from the sociodemographic context chapter of the doctoral thesis entitled,". The analysis focuses on the conditions of the social organization of care in Costa Rica, and explains the crisis generated by the lack of social co-responsibility on carework in the country. Situation that generates tensions within households, and has a direct effect mainly in women, and particular in migrant Nicaraguan female heads of

Key words: social organization of care; domestic labor and carework; global care chains; feminization of migration; female households 


\section{Problematización de una tensión estructural}

Durante la época preindustrial en Europa, las personas participaban en la sociedad según su género, su edad y de acuerdo con el contexto económico en los trabajos para la producción y para la reproducción social (Borderías, Carrasco y Torns 2011).

De acuerdo con Engels ([1884] 1966), con la introducción de la época industrial, los roles y las funciones de cada individuo cambiaron según las nuevas demandas de la sociedad. Este proceso acentuó la división social y sexual del trabajo, además de la utilización de esclavos para satisfacer las nuevas demandas productivas (Engels [1884] 1966).

Anterior a esa etapa, las mujeres participaban en las labores domésticas; sin embargo, fue desde el proceso de industrialización que se le confinó al espacio familiar para que realizaran exclusivamente las labores de reproducción social. Este hecho inauguró la demarcación de la división sexual del trabajo y relegó a las mujeres al espacio familiar; en contraposición, se estableció el trabajo productivo para los hombres como la forma privilegiada de organización social y productiva. Se describe este proceso a continuación:

en el nuevo régimen monetario, sólo la producción-parael-mercado estaba definida como actividad creadora de valor, mientras que la reproducción del trabajador comenzó a considerarse algo sin valor desde el punto de vista económico, e incluso dejó de ser considerada un trabajo. El trabajo reproductivo se siguió pagando -aunque a valores inferiores- cuando era realizado para los amos o fuera del hogar. Pero la importancia económica de la reproducción de la mano de obra llevada a cabo en el hogar, y su función en la acumulación del capital, se hicieron invisibles, confundiéndose con una vocación natural y designándose como «trabajo de mujeres» [...] La separación entre producción y reproducción creó una clase de mujeres proletarias que estaban tan desposeídas como los hombres, pero a diferencia de sus parientes masculinos, en una sociedad que estaba cada vez más moneti- 
zada, casi no tenían acceso a los salarios, siendo forzadas así a la condición de una pobreza crónica, la dependencia económica y la invisibilidad como trabajadoras (Federici 2010, 112-113).

En ese sentido, Federeci (2010) desarrolla un análisis más puntutal sobre la exclusión y la desigualdad que experimentaron las mujeres con esta nueva orgazación económica y social. Sin embargo, Engels ([1884] 1966) inaugura el debate sobre la formación de la división sexual del trabajo a partir de la dicotomía reproducción/producción, quien desde una perspectiva materialista realiza las primeras explicaciones sobre la subordinación de las mujeres en el contexto capitalista. Engels ([1884] 1966) asegura que la reclusión de la mujer en el espacio privado fue su gran derrota, gracias a la aparición de la propiedad privada, la producción y la división social y sexual del trabajo. El espacio familiar, por lo tanto, careció de valor social con relación al trabajo productivo (Engels [1884] 1966).

Dalla Costa y James (1972) también recalcan cómo el sistema capitalista destruyó la forma previa de entender a la familia, a la comunidad y a la producción como un todo. Desde ese momento, se concentran los medios de producción y se separa al hombre de la familia para convertirlo en fuerza productiva.

Jelin (2014) expone el argumento de Saffioti (1969), quien asegura que desde que se implementó el sistema capitalista se comenzó el papel marginal de las mujeres dentro de la sociedad, al disminuirlas de su participación en las tareas productivas que realizaban previamente. De esta forma, se apeló a su condición de mujer en términos biológicos para convertirla en mano de obra gratuita y justificar su explotación. Además, al estar proscrita al espacio familiar, su posibilidad de reivindicación se vio fuertemente aminorada, y fue más proclive a la explotación (Jelin 2014). Por lo tanto, el capitalismo le otorgó un énfasis decisivo a la producción y a la reproducción social a partir de dos clases, como se muestra a continuación:

de una parte, la producción de medios de existencia, de productos alimenticios, de ropa, de vivienda y de los instrumentos que para producir todo eso se necesitan; de otra parte, la producción del hombre mismo, la continuación de la especie. El orden social en que viven los hombres, en una época o en un país dados, está condiciona- 
do por esas dos especies de producción: el grado de desarrollo del trabajo, por una parte; y la familia, por la otra. Cuanto menos desarrollado está el trabajo, más restringida es la cantidad de sus productos; y, por consiguiente, la riqueza de la sociedad, con tanta mayor fuerza se manifiesta la influencia dominante de los lazos de parentesco sobre el régimen social (Engels [1884] 1966, 1).

En ese sentido, el marxismo fue la corriente teórica que visibilizó el trabajo doméstico o el trabajo reproductivo como una forma de explotación dentro de las relaciones sociales y económicas del capitalismo. Sin embargo, Engels (1966) se refirió a este tipo de trabajo como carente de valor social; y, por ende, carente de plusvalía.

En contraposición, las feministas marxistas, más adelante, aseguraron que ese tipo de trabajo sí tiene un valor social porque puede transformar productos que son mercancías. Esto implica que es un tipo trabajo necesario para la reproducción de la fuerza de trabajo porque tiene la capacidad de generar transferencia de valor (Sánchez Arias 2013; Uría, Pineda y Oliván 1985).

Jelin (2014) recurre, además, a Larguía y Dumoulin (1976) para ampliar la teoría sobre el papel de los modos de reproducción social dentro del capitalismo. En ese sentido, ellas aseguraron que la fuerza de trabajo para la reproducción del sistema capitalista son los seres humanos, por eso, garantizar su existencia radica en la reproducción social.

Larguía y Dumoulin (1976) propusieron resolver la articulación entre trabajo doméstico, familia y división sexual del trabajo; y al mismo tiempo, vincularlo con la estructura productiva capitalista. De esta forma, desarrollaron el concepto de labor doméstica que se desarrolla enseguida:

el conjunto de tareas, habituales y repetitivas en su mayor parte, que asegura la reproducción social en tres sentidos: 'la reproducción estrictamente biológica', que en el plano familiar significa gestar y tener hijos (y en el plano social se refiere a los aspectos socio-demográficos de la fecundidad), la organización y ejecución de las tareas de 'reproducción de la fuerza de trabajo consumida diariamente' [...] y la 'reproducción social', o sea las tareas dirigidas al mantenimiento del sistema social, especialmente 
en el cuidado y la socialización temprana de niños, enfer-

mos y ancianos (Jelin 2014, 25).

Borderías, Carrasco y Torns (2011) también realizan una genealogía sobre la evolución del debate feminista acerca de la reproducción social y del trabajo doméstico, el cual despuntó ampliamente a finales de los sesenta y durante de la década de los setenta del siglo pasado. El debate compartió los siguientes preceptos.

En primer lugar, consideraron que la reproducción biológica se encuentra vinculada con la construcción social de la maternidad en cada sociedad. Segundo, ellas revelaron que, dentro de la reproducción de la fuerza de trabajo, se incluyen además procesos de educación y de aprendizaje. Por último, se concentraron en analizar que, dentro de la satisfacción de necesidades de cuidados, se incluye la participación del Estado, del mercado y de los hogares (Dalla Costa y James 1972; Jelin 2014; Molyneux 1979).

Himmelweit [1995] (2011) asegura que, en ese momento, la economía feminista le incorporó, al análisis sobre el trabajo asalariado, la categoría de trabajo doméstico como una forma de trabajo comparable al trabajo remunerado. Este por cuanto el trabajo doméstico es una actividad que tiene por objetivo final la reproducción de la especie humana, por ejemplo: tener «comidas cocinadas, casas limpias y traseros pulcros» (Himmelweit 2011, 202), los cuales consumen tiempo y energía. Segundo, es trabajo porque «debe poder participar potencialmente en alguna forma de división del trabajo» (HimmeIweit 2011, 206). Por último, este tipo de trabajo es separable de la persona quien lo realiza y puede ser otorgado a una tercera persona.

En resumen, este debate con sus diferentes matices ha concluido que el trabajo realizado a lo interno de los hogares se ha mantenido invisibilizado y sin remuneración, a fin de sacar provecho. Para el capitalismo, es necesario que este nexo permanezca así porque disminuye los costes económicos y sociales (fuerza de trabajo y el mantenimiento de la población) de la reproducción social, elemento primordial para la proliferación del mismo sistema (Borderías, Carrasco y Torns 2011).

En ese sentido, dicho debate estableció las diferencias entre trabajo remunerado y no remunerado en oposición a la noción economista del empleo. Por lo tanto, la reproducción social es concebida como un sistema que integra la estructura familiar, el trabajo asalariado, el no asalariado, el Estado en su papel de reproducción de la población, la fuerza de trabajo y las organizaciones sociales y económicas que regulan los diferentes trabajos (Borderías, Carrasco y Torns, Teresa 2011).

De esta forma, las feministas del norte global se abocaron a estudiar este fenómeno y empezaron a problematizarlo y a visibilizarlo. Por ejemplo, visibilizaron el trabajo de las mujeres a lo interno de los hogares, 
demostraron la existencia de desigualdades que enfrentan las mujeres cuando se incorporan al espacio público e impulsaron el debate sobre el trabajo de reproducción social para la organización social y económica de las sociedades (Himmelweit 2011). Sin embargo, desde finales de los ochenta y durante la década de los noventa algunas feministas, como Hochschild [1983] (2003), Folbre (1995), Himmelweit (1999; 2011), ampliaron los análisis sobre el concepto de cuidado / 'care'. Ellas comenzaron a reflexionar a partir de los elementos emotivos y afectivos en la relación de los cuidados, y analizaron su importancia para la reproducción social de la vida.

Tal debate posicionó el afecto en el trabajo de los cuidados como una labor necesaria para el desarrollo de las personas en términos de la socialización primaria, en la adquisición de una identidad y del bienestar físico y emocional de las personas para la reproducción de la fuerza de trabajo.

En general, el debate es amplio, pero Arriagada y Todaro (2012) señalan las diferencias fundamentales entre el trabajo doméstico y el trabajo de los cuidados. Para ellas, el límite entre estos es difícil de distinguir. No obstante, el trabajo doméstico es considerado exclusivamente como una dimensión material, mientras que el de los cuidados implica una yuxtaposición de facetas materiales e inmateriales que se realiza dentro de los hogares.

Esa controversia demostró que la reproducción social no abarca todos los componentes que involucra el trabajo que se realiza a lo interno de los hogares. En este sentido, a través del concepto de care o cuidados, se amplía el análisis de las relaciones sociales que se desarrollan dentro de las familias, las cuales involucran procesos que envuelven la emocionalidad y la afectividad entre las personas (Himmelweit 1999).

Ahora bien, es importante señalar que el concepto care o cuidados se ha enmarcado en tres corrientes teóricas, y su aplicación empírica se ha desarrollado, más que todo, en Gran Bretaña y en Escandinavia (Daly y Lewis [2000] 2011). De acuerdo con Daly y Lewis (2011), una primera vertiente se centra en los aspectos relacionales del cuidado (Finch y Groves 1993; Graham 1991; Thomas 1993; Wareness 1984). Ellas mencionan una segunda corriente respecto a otros análisis que se han enfocado en las prestaciones y servicios relacionados al cuidado (Alber 1995; Anttonen y Sipillä 1996; Evers y Svetlik 1993; Ungerson 1997). Por último, señalan los estudios sobre la consideración de los cuidados alrededor de la dependencia y de la autonomía como tercera corriente (Knijn y Kremer 1997).

En las últimas dos décadas, se pueden identificar en América Latina diferentes esfuerzos que analizan el trabajo de los cuidados. Por un lado, sobresalen las investigaciones elaboradas por personas investigadoras como Martínez Franzoni (2008); Martínez Franzoni y Voorend (2009), quienes estudian la articulación entre los regímenes de bienestar, (Esping-Andersen 1990); y, por otro lado, los órdenes de género (Walby 1997) en la vida cotidiana de las personas. 
El segundo estudio antes mencionado demuestra cómo las sociedades se encuentran constituidas «en torno al género como organizador jerárquico de diferencias basadas en el sexo de las personas. A la vez, reconoce que el patriarcado no existe desprovisto de acuerdos sociales y de Estados que, al regular, reproducen o vulneran dicha estratificación» (Martínez Franzoni y Voorend 2009, 17).

Esos estudios cuantitativos dan cuenta de las relaciones desiguales de género tanto en el espacio familiar como en el espacio público. Además, articulan esta relación con los Estados y los mercados de la región latinoamericana.

También se ha desarrollado una serie de estudios financiados por ONU-Mujeres sobre las cadenas globales de cuidado para América Latina y España. Se identifica una pesquisa enfocada en España de Pérez Orozco y López Gil (2011); otra sobre Costa Rica-Nicaragua (Carcedo, Lexartza y Chaves Groh 2011); otra sobre Paraguay-Argentina (Sanchis y Rodríguez Enríquez 2010); y, por último, una de Chile-Perú (Arriagada y Todaro 2012).

También, se recalca la trayectoria de Herrera Mosquera (2013; 2011) a partir de las investigaciones que ha efectuado sobre mujeres ecuatorianas en Europa. Herrera Mosquera $(2013 ; 2011)$ analiza los vínculos entre la desigualdad, los cuidados y los cambios en las familiares a partir de la experiencia migratoria de mujeres ecuatorianas a Europa. Asimismo, se identifican investigaciones en el cono sur (Calquín 2014; Gonzálvez Torralbo 2013; Pedone 2008; Rodríguez Enríquez 2007) y en Centroamérica (Carcedo, Lexartza, y Chaves Groh 2011; Hernández Cordero 2016; Hidalgo Xirinachs 2016; Lexartza Artza 2010).

En España, sobresalen los aportes de Pérez Orozco (2006b; 2006a; 2009) quien, desde la economía feminista, explica la evolución de la reproducción social, aborda la crisis en la organización social de los cuidados (OSC) y reabre el debate teórico para proponer nuevas herramientas con el fin de pensar la economía y las relaciones sociales de manera distinta.

En resumen, estas investigaciones parten del supuesto de que el rol subordinado de las mujeres en las sociedades capitalistas se genera producto de las construcciones culturales y sociales alrededor de la figura de la mujer, las cuales justifican o sustentan la división sexual del trabajo y el rol de la maternidad.

En ese sentido, se genera una exaltación de los deberes de la "femineidad" asociados a sus funciones biológicas; y de esta forma, se le aminora su condición de sujeto y su autonomía con relación al Estado y a la sociedad (Chaves Jiménez y Fernández Fernández 2016; Cobo Bedia, Rosa et al. 2009).

Por último, se destaca el debate sobre el trabajo de los cuidados con relación a la reproducción social continúa reelaborándose. Sin embargo, este continúa actualizándose, puesto que encierra un punto de inflexión entre la noción económica actual, las condiciones materiales y simbólicas de las personas y 
las relaciones de poder y las discriminaciones que experimentan, sobre todo, las mujeres dentro y fuera del hogar.

Así pues, se toma la siguiente definición porque integra todas las facetas superpuestas de lo que representa hacer el trabajo de los cuidados.

Se designará aquí a la gestión y a la generación de recursos para el mantenimiento cotidiano de la vida y de la salud de las personas, así como la provisión diaria de bienestar físico y emocional que satisfacen sus necesidades a lo largo del ciclo vital. El cuidado se refiere a bienes, servicios y actividades que les permiten a las personas alimentarse, educarse, estar sanas y vivir en un hábitat propicio (Arriagada y Todaro 2012, 24).

En suma, el trabajo de los cuidados al igual que el doméstico se deben analizar porque son imprescindibles para la reproducción y el mantenimiento de la humanidad, los cuales se realizan a lo largo de la vida y contienen intensidades distintas durante todos los momentos del ciclo vital (Arriagada y Todaro 2012).

\section{Cadenas globales de cuidados, feminización de la migración y transformaciones familiares}

Recién se evidenció la existencia de una tensión entre el sistema capitalista y la reproducción social de la fuerza de trabajo. Esta es instituida por medio de la división sexual del trabajo e implementada a través de roles de género que demarcan la subjetividad y la identidad de las personas, sobre todo de las mujeres, para que sean ellas quienes lo realicen. Dentro de la lógica mercantil, el trabajo de los cuidados es considerado como residual y se sustenta en el amor y en el sacrificio de las mujeres, pero, sobre todo, en el de la maternidad.

Por esa misma razón, el desempleo, la pobreza y la precariedad laboral es más abismal en las mujeres latinoamericanas. Verbigracia, de acuerdo con el observatorio de igualdad de género de la CEPAL, en el año 2017, por cada 100 hombres que vivían en hogares pobres en la región, había 113 mujeres en similar situación. Esto evidencia la falta de autonomía económica de las mujeres, quienes, en ausencia de otros ingresos del hogar, son más proclives a estar en situación de pobreza, realidad que se agudiza en hogares con mayor presencia de niños y niñas (CEPAL 2017, 3).

En este orden de ideas, el Observatorio de Igualdad de Género de América Latina y el Caribe comprobó que, para el año 2017, la proporción de mujeres sin ingresos propios alcanzaba un promedio de $29 \%$ mientras que para los hombres esta cifra era de $10,5 \%$ lo cual representa casi un tercio de las mujeres de la región (CEPAL 2017). En el caso de Costa Rica, esta proporción es aún más abismal; en mujeres es $32,7 \%$, mientras que en hombres es 10,5\% (CEPAL 2017). 
La vida en la región latinoamericana se desarrolla a través de tensiones latentes que se producen por no existir oportunidades suficientes para garantizarse los recursos necesarios con el objetivo de mantener la vida (Carcedo et al. 2011; Herrera Mosquera 2011; Sanchis y Rodríguez Enríquez 2010). Por ejemplo, un informe publicado por Naciones Unidas (2017) asegura que, a partir de la primera mitad de la década del 2000, muchos países de la región han visto deteriorados sus mercados laborales. Según la CEPAL, se estima que:

Entre 2014 y 2017, la tasa de desempleo abierto urbano habrá aumentado 2,5 puntos porcentuales, lo que implica que, solo en las zonas urbanas, casi 23 millones de personas no pueden acceder a un empleo. Además, los empleos que se generan en este contexto suelen ser de baja calidad y se ha avanzado muy poco en la reducción de las disparidades, ya que las tasas de desempleo de las mujeres y personas jóvenes siguen superando marcadamente a las de hombres y adultos (Naciones Unidas 2017, 8).

Algunos motivos de la precarización de las condiciones de vida en estas latitudes son atribuidos a la incorporación de los Planes de Ajuste Estructural y a las reformas neoliberales (Pérez Orozco 2007) que, desde la década de los ochenta, se implementaron en la región. Estas medidas han repercutido en el incremento de la violencia, en la falta de opciones de empleo y en la precarización salarial que no permiten la reproducción social básica de las familias latinoamericanas.

Como consecuencia, se identifica una creciente feminización de la migración en las estadísticas de la región, lo que conlleva a identificar movimientos más autónomos de mujeres migrando (Herrera Mosquera 2013). Las mujeres, en el mundo, representan aproximadamente $48 \%$ de toda la población migrante internacional; sin embargo, existen diferencias entre cada región, «Europa presenta el porcentaje más alto de mujeres migrantes $(51,9 \%)$, seguida de América Latina y el Caribe $(51,6 \%)$, América de Norte $(51,2 \%)$, Oceanía $(50,2 \%)$, África $(45,9 \%)$ y Asia $(41,6 \%) »$ (DAES 2013, 2).

Sumado a este fenómeno, se le suma la crisis en la organización social de los cuidados (OSC) que se genera en los países del Norte global y en algunas latitudes de América Latina, como es el caso de Costa Rica. 
La crisis en la OSC se genera por varios factores entrelazados entre los que destacan factores estructurales como «la participación creciente de las mujeres en el mercado de trabajo, las transformaciones familiares y laborales y la evolución demográfica y epidemiológica» (Arriagada y Todaro 2012, 27). También, depende de factores culturales, sociales y económicos que inciden en el tipo de organización social de los cuidados que se generan a través de diferentes regímenes de cuidado. En América Latina, destaca el familista, el cual atribuye la mayor carga o responsabilidad del cuidado en las mujeres de la familia (Arriagada y Todaro 2012).

Al estar organizado socialmente el cuidado en las mujeres de los hogares, la tensión entre trabajo y familia aumenta para ellas. Esta tensión es generada, principalmente, por la incorporación de las mujeres al espacio público, lo cual ha significado un reordenamiento de los roles y de las tareas desempeñadas dentro de las familias. En ese sentido, el Estado, el mercado y la sociedad en general continúan sin priorizar el debate sobre la OSC.

Este tipo de trabajo es básico para la reproducción social de la vida, pero al haber sido invisibilizado por tanto tiempo, se han generado tensiones al momento de querer organizarlo. Este vínculo es conflictivo y ha producido una mercantilización y externalización de las formas en cómo se distribuyen los cuidados (Sanchis y Rodríguez Enríquez 2010).

El problema en la distribución actual de la OSC radica en el contenido feminizado de este tipo de trabajo, el cual el sistema aprovecha para absorber a las mujeres más empobrecidas, sobre todo migrantes, para que sean ellas quienes lo realicen, en condicione precarias y con baja remuneración económica.

Además, por ser un trabajo feminizado, con poco valor social y realizado de forma remunerada fundamentalmente por mujeres migrantes, conlleva a que se genere en condiciones de irregularidad en términos de derechos laborales, y, que sea poco regulado por los Estados.

Un ejemplo del valor conferido a dicho trabajo se constata en el Código de Trabajo de Costa Rica de 1943, intrumento todavía vigente en el país. En ese momento, fue considerado un código de avanzada para la época; sin embargo, establecía casos de excepción, entre los cuales, destacaba el trabajado doméstico (Código de Trabajo de Costa Rica 1943).

De acuerdo con la entrevista realizada en el año 2016 a Álvaro Moya, en ese entonces abogado de la Asociación de trabajadoras domésticas (ASTRADOMES), él asegura que el código establecía la posibilidad de interrumpir el trabajo doméstico hasta por dos horas y volver de nuevo. Este imponía la jornada total de la trabajadora doméstica como la sumatoria del trabajo extraordinario y del ordinario, el cual no podía exceder las 14 horas. Tal práctica legitimada por el Estado costarricense se postergó hasta el año 2009, año en que ASTRADOMES logró la implementación de la nueva ley de trabajo doméstico 
remunerado, después de dos décadas de lucha por el reconocimiento de sus propios derechos como trabajadoras.

Por lo tanto, la crisis de la reproducción social en los países más pobres se combina con la crisis en la OSC de los países con mayor desarrollo social y económico, lo que conlleva a la formación de las cadenas globales de cuidados (Ehrenreich y Hochschild [2000] 2002).

Este es un concepto desarrollado por Ehrenreich y Hochschild (2002), el cual involucra una serie de vínculos personales entrelazados de trabajos pagados y no pagados entre las personas alrededor del mundo. Herrera Mosquera las define de la siguiente forma:

se refiere precisamente a aquellos procesos de transferencia de cuidado de carácter global, existentes generalmente entre mujeres y entre países, que se forman con el objetivo de sostener cotidianamente la vida, en la que los hogares (las mujeres) transfieren cuidados sobre la base de relaciones transnacionales que se levantan sobre determinados ejes de poder relacionados con la clase, el género, la etnicidad, y que tienen como resultado que algunas personas gozan de cuidados privilegiados y otras más bien experimentan déficit de cuidados (Herrera Mosquera 2013,19$)$.

Las cadenas globales de cuidados contienen varios procesos entrelazados. De acuerdo con Yeates (2005), involucra la externalización del trabajo de los cuidados como trabajo asalariado; además, las contrataciones de este tipo de trabajo implican la movilización de mano de obra precarizada a través de redes informales y del mercado. Estas redes revelan que el mercado contiene una estructura de segregación racial, de clase y de género que funcionan de manera entrelazada (Herrera Mosquera 2013; Sassen, Saskia 2003). También Yeats (2005) asegura que este concepto explica cómo dentro de los hogares se desarrollan estrategias internacionales para mantener la vida de las familias por medio de redes de carácter transnacional, al tiempo que se refleja la interseccionalidad de las desigualdades que se relacionan con la imbricación entrelazada de la clase, el estatus, la etnicidad y el género (Ehrenreich y Hochschild 2002; Yeates 2005). 
Lo más significativo del desarrollo de ese concepto es que describe el papel esencial de las mujeres en el fenómeno migratorio en el cual ellas son el eslabón prioritario de la responsabilidad de asegurar la sostenibilidad de la vida de los hogares en contextos de crisis (Pérez Orozco 2007).

En ese sentido, muchos estudios dan cuenta de que existen dinámicas de cuidados enlazadas de manera transnacional, y que, al mismo tiempo, se está generando un incremento paulatino de mujeres del sur global migrando autónomamente como la única salida a la crisis (Anderson 2000; Calquín 2014; Ehrenreich y Hochschild 2002; Herrera Mosquera 2013; Hondagneu-Sotelo 2001; Parreñas 2001; Pedone 2008).

Según Herrera Mosquera (2012), las cadenas de cuidados han permitido comprender y conectar las realidades estructurales de las sociedades de destino con las de origen. Asimismo, este concepto enfatiza las implicaciones por el carácter asimétrico de las relaciones sociales en cada etapa de la cadena de cuidado y, además, evidencia que el género es un eje articulador de estas desigualdades, lo cual permite desnaturalizar el trabajo doméstico como una actividad estrictamente femenina por su vinculación al trabajo reproductivo (Herrera Mosquera, 2012).

Este concepto ha sido utilizado primordialmente para estudiar la inserción de las mujeres migrantes en el país del destino. Este tipo de investigaciones se han centrado en los beneficios para la estructura laboral y las implicaciones para la estructura de servicios de orden global marcadas por desigualdades entrelazadas de género, raza y etnicidad (Constable 1997; Hondagneu-Sotelo 2001; Parreñas 2001; Silvey 2004).

También, se identifican investigadoras que se han enfocado en el análisis de las dinámicas y los vínculos afectivos que se generan entre las familias contratantes y las mujeres migrantes (Guitiérrez-Rodríguez 2010; 2004). Sin embargo, existen críticas a este concepto; entre las que rescato, se hallan las de Herrera Mosquera (2012), quien menciona que las cadenas globales de cuidados se centran en señalar un solo tipo de migración femenina y un solo tipo de cuidados. Se reivindica esta crítica porque ella señala la falta de precisión o de interés por estudiar todos los elementos involucrados para entender el desarrollo de la organización del trabajo de los cuidados a lo interno de las familias de las mujeres migrantes (Herrera Mosquera 2012).

A continuación, se enmarca el contexto socioeconómico de Costa Rica en términos del fenómeno de la feminización de la migración con relación a los cambios acontecidos en la composición de las estructuras de las familias costarricenses. De esta forma, se puede analizar las implicaciones de esta crisis para las mujeres migrantes, sobre todo nicaragüenses, que se insertan al mercado formal e informal costarricense como trabajadoras domésticas remuneradas. 


\section{Migración en Costa Rica}

Según la Organización de las Naciones Unidas, la migración está aumentando en el mundo, por ejemplo, en el año 2013 se registraron 232 millones de migrantes (DAES 2013). En América Latina, 25 millones de personas residen fuera de su país de nacimiento, y 15 millones de estos han emigrado en las últimas dos décadas (DAES 2013). Sin embargo, en la región centroamericana, el porcentaje de migrantes cuadriplica la estimación mundial, y son parte de migraciones intra- y extrarregionales (Sandoval García 2015).

Entre los países centroamericanos que más personas expulsan, se encuentran: El Salvador (15\%), Nicaragua (13\%) y Honduras (12\%) con porcentajes de población que viven en el exterior. Estados Unidos es el principal destino para la migración; no obstante, Costa Rica es el principal receptor de migraciones interregionales, especialmente provenientes de Nicaragua (Morales Gamboa 2011).

En la región centroamericana, se han desencadenado procesos de migración como consecuencia de "las políticas neoliberales, procesos de migración forzada y, simultáneamente, el incremento de controles migratorios, entre los cuales se puede citar la externalización de fronteras, el cumplimiento de la ley (Law enforcement), entre otros" (Sandoval García 2015, xxii).

Las nuevas formas de acumulación y de distribución de corte neoliberal han producido en la región frescas fuentes de excedentes producto de las remesas de migrantes internacionales y de las recientes actividades vinculadas al comercio, a los servicios y a las exportaciones no tradicionales (Hidalgo Xirinachs 2016). La consecuencia es el ajuste del mercado laboral caracterizado por el autoempleo de baja productividad, la flexibilidad laboral y la expulsión de la población hacia el exterior (Hidalgo Xirinachs 2016; Morales Gamboa 2011; Pérez Sáinz y Mora Salas 2007).

Costa Rica, por el contrario, es un país que recibe migrantes. Se ha identificado una evolución de la inmigración significativa, debido a que, para el año 1973, el porcentaje de personas nacidas en el extranjero representaba 1,19\%; para el año 2011, esta cifra aumentó a 8,97\% del total de población que vive en Costa Rica (Gatica López 2013).

El mayor incremento de inmigrantes latinoamericanos se generó entre las décadas de los ochenta y noventa. Entre las causas, destacan la persecución por origen étnico, político, por desastres naturales, por guerra o por reunificación familiar; sin embargo, hoy en día prevalece la búsqueda de un ingreso como razón principal en el movimiento migratorio hacia Costa Rica (Gatica López 2013).

La mayor cantidad de migrantes que viven en el país provienen de Nicaragua. En el año 1973, había 11871 nicaragüenses; en 1984, incrementó a 45 918; en el 2000, se registraron 226 374; y para el 2011, el número ascendió a 287766 (Gatica López 2013). 
El último censo del año 2011 registró 385899 extranjeros (8,97\%). 74,57\% (287 766 habitantes) provienen de Nicaragua; 4,28 \%, de Estados Unidos y Canadá (17 577 personas); y de otros países, como Colombia (16 514 habitantes, 4,28 \%), y países centroamericanos como El Salvador (9424 pobladores, 4,12\%) o Panamá (11 250 habitantes, 2,92\%) (INEC, 2012).

Figura 1

Costa Rica. Población nacida en el extranjero. Año 2011

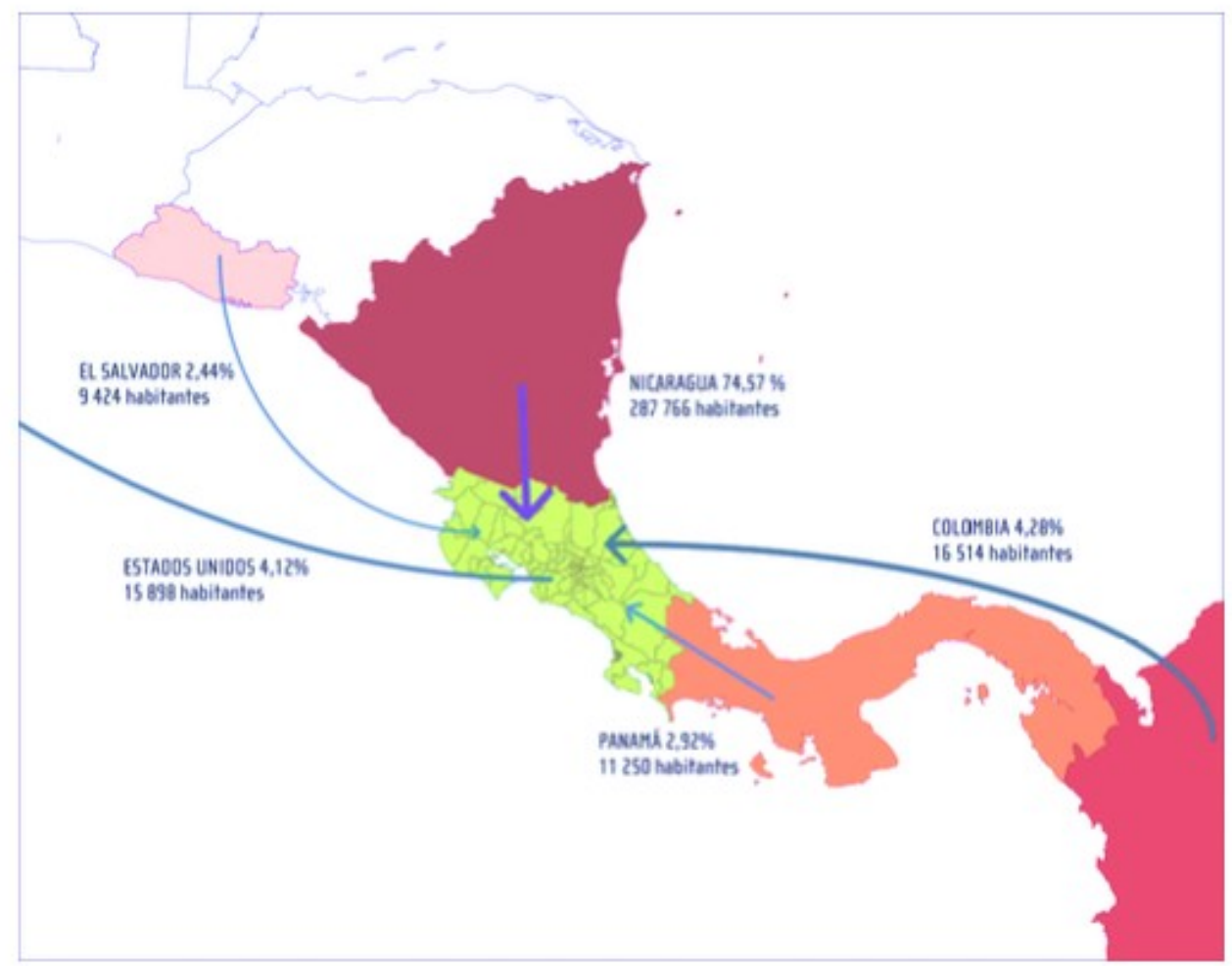

Fuente: INEC 2011.

Del total de personas nacidas en el extranjero en el país, $48 \%$ corresponde a hombres (186 111 inmigrantes); y 52\%, a mujeres (199 788 inmigrantes). Estos datos se mantienen desde el año 2000 (INEC 2011a).

Respecto a la distribución geográfica, se constata que, aproximadamente, $38 \%$ de la población migrante se ubica en San José. Sin embargo, 54\% de las personas nacidas en el extranjero que viven en San José son mujeres (Consejo Nacional de Migración 2013).

Por lo tanto, se debe analizar la feminización de la migración en Costa Rica, porque las mujeres representan más de la mitad del porcentaje total de per- 
sonas extranjeras que vive en el país, y, además, se observan dinámicas propias para desplazarse hacia Costa Rica.

Feminización de la migración. Mujeres nicaragüenses en Costa Rica

La población inmigrante en Costa Rica representa $12,3 \%$ del total de población ocupada. Según Morales Gamboa (2011), el país ha requerido de esta población como fuerza de trabajo insertada en segmentos no especializados del mercado laboral.

Tabla 1. Costa Rica. Total de personas ocupadas costarricenses y extranjeras. Números absolutos y relativos. Año 2011

\begin{tabular}{lcc}
\hline \multirow{2}{*}{ Ocupados } & \multicolumn{2}{c}{ Cantidad } \\
\cline { 2 - 3 } & Números absolutos & Números relativos \\
\hline Ocupados nacidos en Costa Rica & 1465450 & 87,7 \\
Ocupados nacidos en el extranjero & 205182 & 12,3 \\
Total & 1670632 & 100 \\
\hline
\end{tabular}

Fuente: Guerrero, Montero, Muñoz y García 2012.

Guerrero Segura et al. (2012) aseguran que la población inmigrante se concentra en sectores productivos como la agricultura, la ganadería, la silvicultura y la pesca (18\%), seguido del sector comercial $(16,5 \%)$, la industria manufacturera y la construcción (11\%), el alojamiento y los servicios de comida $(8,3 \%)$ y los servicios domésticos $(10,1 \%)$.

Específicamente, las mujeres migrantes, en especial las nicaragüenses, se ubican en sectores productivos asociados a los roles tradicionales de género, como el trabajo doméstico, los servicios en el sector turismo y en empaquetaría de empresas agroexportadoras (Castro 2007; Hidalgo Xirinachs 2016).

Ese fenómeno se genera como una consecuencia de la actual Ley de Migración 8764 porque, en el artículo 100, señala que los trabajadores migrantes se deben incorporar en ocupaciones específicas que se vinculen con las recomendaciones del Ministerio de Trabajo y de Seguridad Social (MTSS) (Asamblea Legislativa de Costa Rica 2009). Sin embargo, de acuerdo con Chaves Groh (2013), los documentos no señalan cuáles son estas ocupaciones específicas autorizadas; por lo tanto, las personas no tienen conocimiento si están acreditadas para solicitar un permiso de trabajo previo al trámite. Además, la investigadora asegura que solo se están entregando permisos para el trabajo doméstico remunerado en caso de las mujeres nicaragüenses, lo cual no permite mejorar sus ingresos económicos (Chaves Groh 2013). 
1. El salario rural en Costa Rica supera en USD 5 a USD 7 al de Nicaragua. En la zona urbana, el trabajo doméstico en Costa Rica supera entre USD 50 y USD 100 lo que se paga en Nicaragua (Carcedo, Lexartza y Chaves Groh 2011)
Otra de las causas principales de la migración de mujeres nicaragüenses está relacionada con el crecimiento sostenido de las jefaturas de hogar femeninas en Nicaragua (Carcedo, Lexartza y Chaves Groh 2011). En Nicaragua, en el año 1995, las jefaturas femeninas urbanas representaban $32,7 \%$ del total de las jefaturas de hogar; pero para el 2000 , esta cifra aumentó a 43,6\%. En el área rural, incrementó de 19,6\% a 30\% en el mismo periodo (Carcedo, Lexartza, y Chaves Groh 2011); de cada 100 mujeres que emigran, 46 son jefas de hogar; y la edad promedio es de 33 años (Carballo Meza y Castro Quintanilla 2011).

La causa esencial de la migración de las jefas de hogar nicaragüenses está relacionada con la posibilidad de mantener a sus familias. Según Carcedo, Lexartza y Chaves Groh (2011), otra razón de la migración de mujeres es la violencia de género, puesto que identificaron que una de cada cuatro mujeres asegura que ha dejado Nicaragua por problemas familiares o dentro del matrimonio, lo que confirma la violencia contra las mujeres como un factor de migración de las nicaragüenses.

Esta misma investigación señala que otra razón de peso de mujeres migrantes nicaragüenses que trabajan en Costa Rica ha sido las diferencias salariales entre ambos países ${ }^{1}$, así como la cercanía geográfica que facilita la comunicación entre las mujeres migrantes y sus familias en Nicaragua.

Sin embargo, Hidalgo Xirinachs (2016) señala que el proyecto migratorio de estas mujeres nicaragüenses se desenvuelve a través de contradicciones intrínsecas para la vida de ellas, puesto que, al tiempo que experimentan más autonomía en sus movimientos, la migración se afronta como un reto porque las expone a nuevas formas de discriminación y de explotación por el hecho de ser mujeres, migrantes y trabajadoras. "La ocupación laboral de más del $90 \%$ de las mujeres migrantes está concentrada en el trabajo doméstico asalariado y no asalariado» (Carballo Meza y Castro Quintanilla 2011, 17).

Las mujeres nicaragüenses que migran hacia Costa Rica para obtener una posibilidad de ingreso de dinero a fin de mantener a sus familias deben cumplir con la responsabilidad económica del hogar; pero al mismo tiempo, con su papel como reproductoras del hogar. Esta ambivalencia que integra el núcleo mismo de la crisis de la OSC se resuelve, en los países empobrecidos, a través del apoyo de otras mujeres que se quedan cuidando a sus infantes, reproduciendo de esta forma la continuación de las cadenas globales de cuidados, sustentadas principalmente por mujeres en ambos países. Por su parte, se observa que el porcentaje de población femenina ocupada nacida en el extranjero en Costa Rica es de cerca de 46\% (77 292 mujeres) del total de personas ocupadas inmigrantes (INEC 2017b).

En el informe de Guerrero Segura, Montero Mora, Muñoz Chacón y García Pérez (2012), se indica que las actividades en que se insertan, en gran parte, las mujeres extranjeras se hallan asociadas a la reproducción de los roles de género difundidos en la sociedad. De este modo, se identifica que los traba- 
jos con baja calificación asociados al género femenino en el ámbito público son realizados mayoritariamente por mujeres inmigrantes.

En la reproducción de esos trabajos de baja remuneración económica, se debe de cuidar y reproducir trabajos domésticos, fuera y dentro del propio hogar, dinámica que evidencia la limitación de tiempo y de recursos para demandar o negociar el propio derecho al autocuidado o a espacios sociales para que exista una corresponsabilidad social de cuidado, tanto para ellas como para sus familias.

Al mismo tiempo, en Costa Rica, se han venido generando cambios en los niveles social, político y económico para las mujeres costarricenses. Se destaca, principalmente, los avances en el acceso y en la producción de mecanismos para la participación política de las mujeres, la suscripción de acuerdos internacionales sobre equidad e igualdad de género, así como los avances significativos en el ámbito de la educación educativo (INAMU 2015). En general, la población femenina es más educada que la masculina, desde su participación escolar hasta en la matrícula universitaria, lo cual se refleja en las tasas de participación femenina de las últimas décadas (Carcedo, Lexartza, y Chaves Groh 2011; Estado de la Nación 2002; INAMU 2008).

Ahora bien, la estructura familiar tradicional costarricense se ha transformado con el aumento de los hogares monoparentales cuya jefatura es femenina (MPJF) y los hogares biparentales donde la mujer también sale a trabajar al espacio público (Carcedo, Lexartza y Chaves Groh 2011; Román y Morales 2010).

La incorporación de las mujeres al mercado de trabajo y el aumento en los cambios de las estructuras internas familiares no ha sido acompañada por políticas de organización social de los cuidados; en consecuencia, ha traído el aumento de las dobles y triples jornadas de trabajo para las mujeres o la contratación de otras mujeres para suplir esos trabajos a lo interno de los hogares.

Se constata que $20,5 \%$ de los hogares costarricenses acuden a la contratación de trabajo doméstico remunerado para solventar la reproducción familiar (INAMU 2008). De igual forma, 8 de cada 10 mujeres en Costa Rica tienen demandas de cuidados de personas menores de 12 años (OIT 2010). Asimismo, la Encuesta sobre uso del Tiempo realizada en la Gran Área Metropolitana de Costa Rica (EUT-GAM 2011), en el año 2011, reveló que, dentro de la población económicamente activa (PEA) y la inactiva (PIA), son las mujeres quienes siguen realizando más trabajo doméstico y de los cuidados.

Las mujeres efectúan más del doble de tiempo ese tipo de trabajo que los hombres, y al mismo tiempo, se comprueba las dobles jornadas laborales de las mujeres ocupadas -36:03 horas semanales de trabajo doméstico- (Sandoval et al. 2012). 
Tabla 2. Costa Rica- GAM: tiempo social promedio" ${ }^{1 /}$ semanal de la población de 12 años y más por actividad, según sexo y condición de actividad. Marzo-abril 2011

\begin{tabular}{|c|c|c|c|c|c|c|c|c|}
\hline \multicolumn{9}{|c|}{ Actividad } \\
\hline $\begin{array}{c}\text { Sexo/Co } \\
\text { ndición } \\
\text { de } \\
\text { actividad }\end{array}$ & $\begin{array}{c}\text { Trabajo } \\
\text { remuner } \\
\text { ado }\end{array}$ & $\begin{array}{l}\text { Trabajo } \\
\text { domésti } \\
\text { co no } \\
\text { remuner } \\
\text { ado }\end{array}$ & $\begin{array}{c}\text { Trabajo } \\
\text { de } \\
\text { subsiste } \\
\text { ncia }\end{array}$ & $\begin{array}{c}\text { Trabaj } \\
\circ \\
\text { volunt } \\
\text { ario }\end{array}$ & $\begin{array}{l}\text { Trabajo } \\
\text { domésti } \\
\text { co no } \\
\text { remuner } \\
\text { ado a } \\
\text { otros } \\
\text { hogares }\end{array}$ & $\begin{array}{c}\text { Activida } \\
\text { des de } \\
\text { formaci } \\
\text { ón }\end{array}$ & $\begin{array}{l}\text { Actividad } \\
\text { es de } \\
\text { esparcimi } \\
\text { ento } \\
\text { cultura y } \\
\text { convivenc } \\
\text { ia }\end{array}$ & $\begin{array}{c}\text { Necesida } \\
\text { des y } \\
\text { cuidados } \\
\text { personal } \\
\text { es }\end{array}$ \\
\hline \multicolumn{9}{|l|}{$\begin{array}{c}\text { Hombre } \\
s\end{array}$} \\
\hline $\begin{array}{l}\text { Ocupados } \\
\text { Desocupad } \\
\text { os }\end{array}$ & $48: 40$ & $15: 36$ & $0: 47$ & $0: 24$ & $0: 47$ & $3: 27$ & $36: 59$ & $67: 22$ \\
\hline Inactivos & $0: 00$ & $15: 11$ & $1: 08^{*}$ & $0: 40$ & $0: 55$ & 23:07 & $51: 50$ & $73: 25$ \\
\hline \multicolumn{9}{|l|}{ Mujeres } \\
\hline $\begin{array}{l}\text { Ocupada } \\
\text { s } \\
\text { Desocup } \\
\text { adas }\end{array}$ & $35: 23$ & $36: 03$ & $0: 19$ & $0: 33$ & $1: 09$ & $3: 47$ & $32: 26$ & $69: 09$ \\
\hline Inactivas & $0: 00$ & $38: 23$ & $0: 18$ & $0: 36$ & $1: 31$ & $12: 58$ & 41:04 & 73:16 \\
\hline
\end{tabular}

1" Tiempo en horas semanales se calcula dividiendo el tiempo total que se dedica a determinada actividad entre el total de personas. Expresado en horas semanales.

"Estimaciones con coeficientes de variación mayores al $20 \%$ no son precisos.

Fuente: Sandoval et al. 2012.

Esta encuesta confirmó que, si bien los hombres participan en la realización de las diversas actividades del trabajo doméstico y de los cuidados

el tiempo invertido por las mujeres en su mayoría es siempre mayor que el de los hombres por lo menos en un $65 \%$. Independientemente de la edad, la relación de parentesco con la jefatura de hogar, el estado conyugal, el nivel educativo y si trabaja o no para el mercado (INEC 2011b, 2).

Con base en tales datos, se plantea la interrogante de cómo se resuelve el tránsito entre la esfera pública y privada, en tanto se debe remediar la tensión inherente que recae en las mujeres en general; pero, más específica- 
mente, cómo la solventan las mujeres más vulnerables: las mujeres sin pareja heterosexual, migrantes y de clase social empobrecida.

De igual forma, al existir una creciente demanda de trabajadoras domésticas asalariadas en Costa Rica, las mujeres migrantes experimentan mayor discriminación debido a que se enfrentan a situaciones de irregularidad por el hecho de ser mujeres migrantes.

En ese sentido, a continuación, se analizan los datos del censo 2011, referentes a las jefaturas de hogar de mujeres en costarricenses y las nacidas en el extranjero. Esta información puede ayudar a comprender la relación entre su condición socioeconómica (clase), el país de procedencia (nacionalidad) y su condición de mujer (sexo-género).

\section{Jefaturas de hogar en Costa Rica}

El cambio en la composición de los hogares biparentales con jefatura masculina es un rasgo que se ha venido transformando en América Latina desde finales de la década de los ochenta (Ariza y de Oliviera 2004). En el caso de Costa Rica, se identifica una transformación de la estructura familiar en las últimas tres décadas.

La familia monoparental con jefatura femenina (MPJF), para el año 1990, representaba $17,8 \%$; y, para el año 2008, aumentó en $26,7 \%$. Las familias biparentales con hombre proveedor y cónyuge ama de casa (BPHP) disminuyeron de $62,8 \%$ a $38 \%$ para el mismo periodo. Las familias biparentales con dos proveedores (BPDP) aumentaron de $19,3 \%$ a $35,3 \%$ (Román y Morales, 2010).

En el primer caso (MPJF), se reconoce una continuación del crecimiento porque, en el 2013, aumentó en 36\%. Asimismo, crecieron en $6,6 \%$ en comparación con las jefaturas masculinas, las cuales aumentaron solo 2,5\% (Morales y Román 2013).

Al analizar el estado conyugal de las mujeres jefas, se comprueba una transformación en la estructura familiar. En el año 2013, las jefas de hogar con pareja representaban únicamente $23 \%$ del total de jefaturas femeninas; y, del restante $77 \%, 75 \%$ tenían infantes (Morales y Román 2013).

Para el Estado costarricense, las transformaciones en la estructura familiar deberían de representar retos particulares, ya que el sistema social de derecho se encuentra fundado sobre la tradicional división sexual del trabajo y se mantiene a través de la institución de la familia nuclear. Por lo tanto, las políticas públicas, generalmente, han sido establecidas con base en estos postulados que no siempre satisfacen el bienestar y el trato igualitario para todos los hogares.

Es así como Costa Rica enfrenta disyuntivas cada vez más complejas que obligan a pensar en nuevas formas de institucionalización de las dinámicas sociales como respuesta a la realidad cambiante. Se identifican algunos esfuerzos por parte del Estado costarricense en desarrollar en la última 
década un sistema nacional de atención a la niñez y a la población adulta mayor a través de la implementación de la Red Nacional de Cuido y Desarrollo Infantil (REDCUDI).

En el 2014, la Asamblea Legislativa de la República de Costa Rica aprobó la nueva Ley 9220, Red Nacional de Cuido y Desarrollo Infantil (REDCUDI). Se establece que la finalidad de esta ley consiste en

establecer un sistema de cuido y desarrollo infantil de acceso público, universal y de financiamiento solidario que articule las diferentes modalidades de prestación pública y privada de servicios en materia de cuido y desarrollo infantil, para fortalecer y ampliar las alternativas de atención infantil integral (Asamblea Legislativa de Costa Rica 2014, artículo 1).

Sin embargo, de acuerdo con los informes elaborados por la Defensoría de los Habitantes, la Contraloría General de la República y los resultados de los talleres con los proveedores de servicios organizados por el Estado de la $\mathrm{Na}$ ción (Programa Estado de la Nación 2017; Vargas 2017), la REDCUDI todavía cuenta con severos problemas de funcionamiento (La Defensoría de los Habitantes 2017; Vargas 2017).

Un primer problema que se identifica es el tema de organización, coordinación y trabajo conjunto para que la red funcione como tal. Las investigaciones señalan que existe un consenso entre los prestadores del servicio en que el Instituto Mixto de Ayuda Social (IMAS) no es la institución más idónea para ejecutar este proyecto, porque está enfocado en atender la población en pobreza y pobreza extrema, lo cual impide visualizar a la red como un servicio universal. Asimismo, se identifican deficiencias en la coordinación y en la organización por parte de la Secretaría Técnica de la REDCUDI.

Un segundo problema es la falta de financiamiento. Este se deriva de la mirada asistencialista del proyecto, enfocada en lo social, sin tomar en cuenta que este es un sector de encadenamientos, que afecta a las familias, sobre todo a jefas de hogar, a las comunidades, a las personas trabajadoras y a las empresas (Programa Estado de la Nación 2017). Asimismo, no se concibe el trabajo de cuidados como una labor que genere empleo, y dinamice la economía, sino que se sigue advirtiendo como un sector de asistencia social, lo cual contradice el mismo espíritu de la Ley 9220, cuya meta es una mayor inserción de las mujeres al mercado laboral y un servicio universal. 
En ese sentido, si bien existen iniciativas para la corresponsabilidad social en el cuido con miras a la transformación del régimen de cuidados familista, aún existe una visión masculinista y asistencialista por parte de los tomadores de decisiones en plantearse una real restructuración de la organización social de los cuidados.

Hay otros esfuerzos en el avance de la reorganización social de los cuidados por parte del Estado costarricense, entre los que destacan: la red de atención progresiva para el cuidado integral de las personas adultas mayores (Presidencia de la República de Costa Rica 2012) y la incorporación de la Ley de Contabilización del Aporte del Trabajo Doméstico no Remunerado en Costa Rica 9325 (Asamblea Legislativa de Costa Rica 2015).

Esta última ley permitió, en su proceso de aprobación, el financiamiento de la primera encuesta de uso del tiempo del Gran Àrea Metropolitana en el año 2011(Sandoval Carvajal et al. 2012); y más adelante, su aprobación, en el año 2015, propició el sustento económico para realizar la encuesta nacional de uso del tiempo en el año 2017 (INAMU, INEC 2018), con el fin de visibilizar el aporte de este trabajo, en el PIB nacional, y las desigualdades a razón de tiempo que enfrentan las mujeres en Costa Rica. En ese sentido, el Banco Central estimó el valor económico del trabajo doméstico no remunerado, a través de la cuenta satélite establecida gracias a la Ley 9325, y determinó que, para el año 2017, el trabajo doméstico no remunerado representó $25,3 \%$ (8,3 billones de colones) del Producto Interno Bruto de Costa Rica (Banco Central de Costa Rica 2019).

Por su parte, si se analizan los datos del censo 2011 correspondientes a las jefaturas de hogar femenina migrantes, se constató que, para el año 2011, existían 38883 mujeres jefas de hogar migrantes, quienes representaban $10,48 \%$ de las jefaturas de hogar femeninas del total del país. Entre los datos del censo 2011, también se identifica que, del total de mujeres migrantes, $41,97 \%$ se encontraban inactivas ${ }^{2}$ y $58,03 \%$ (22 564 mujeres) se dedican a distintas ocupaciones: empleada en empresa privada $(27,37 \%)$, empleada de casa particulares $(11,51 \%)$ y como trabajadora por cuenta propia $(11,23 \%)$, 2. Esta cifra puede estar siendo sobrerrepresentada, ya que se pueden encontrar mujeres entre otros.

Esos datos comprueban que muchas de estas mujeres se insertan en actividades feminizadas y de baja remuneración económica. Tales cifras nos dan indicios para pensar que muchas de ellas se encuentran representadas en los índices de hogares pobres y en pobreza extrema. Al mismo tiempo, se considera, en el análisis, la situación de pobreza con respecto a las jefaturas de hogar femeninas y se puede identificar una estrecha relación aún en años posteriores, tanto para nacionales como para extranjeras.

De acuerdo con la Encuesta Nacional de Hogares (2017), el porcentaje total de hogares pobres que se encuentran jefeados por una mujer fue de $44,8 \%$, el porcentaje de pobreza no extrema fue de $44,3 \%$ y en pobreza extrema 46,1\% (INEC 2017a). Estos datos revelan que existe un alto porcentaje de hogares MPJF dentro de los índices de pobreza y de pobreza extrema en 
Costa Rica. Además, evidencian una brecha de género en contra de las mujeres jefas de hogar.

Según el estudio realizado por Quiroga Díaz (2011), las familias MPJF se encuentran en situaciones de pobreza porque, generalmente dentro de estos hogares, hay más personas que sustentar con un único ingreso y que este, al estar feminizado, tiene una baja remuneración económica. Concomitantemente, no hay tantos adultos alrededor para asumir el trabajo de los cuidados de las familias de mujeres jefas de hogar sin pareja, lo que promueve los trabajos informales y la precarización laboral por no tener redes de apoyo para cubrir el cuido de personas dependientes.

En ese sentido, las mujeres migrantes jefas de hogar transitan en un espacio difuso entre la esfera privada de sus propias familias y, en la esfera pública, reproducen el trabajo doméstico y de los cuidados de las familias costarricenses. Dicha situación promueve que los hogares costarricenses tengan más privilegios en la provisión de cuidados debido a que los arreglos familiares de sus propias familias se encuentran más precarizados al no tener suficiente tiempo o ingresos económicos. Por lo tanto, estas mujeres como jefas de hogar sin una pareja heterosexual, así como por su condición de migrante y por su condición socioeconómica, son más vulnerables puesto que no acceden a trabajos con buena remuneración económica por su género y su condición migratoria. Además, se encuentran propensas a enfrentar mayores discriminaciones, expuestas a que sus derechos se vean aminorados y a no contar con seguro social. Todo esto repercute en el desenvolvimiento óptimo de sus familias en tanto que no acceden a tener cuidados dignos y a vivir plenamente y con bienestar.

En virtud de lo anterior, la mayoría de los estudios sobre mujeres migrantes en Costa Rica se han abocado a estudiar las implicaciones que enfrentan las nicaragüenses en el trabajo doméstico remunerado (Hidalgo Xirinachs 2016; Lerussi 2008; Sandoval García, Brenes Montoya y Paniagua Arguedas 2012). Estas investigaciones han señalado las discriminaciones que enfrentan las nicaragüenses producto de las contrataciones informales, a pesar de que se ha modificado la Ley de Trabajo Doméstico.

Estos estudios han mostrado la tensión en el ámbito laboral que se teje con la intersección en las subjetividades que se generan con las personas menores de edad que deben cuidar, así como con los adultos para los que se trabajan (Hidalgo Xirinachs 2016). También, se han identificado abusos sexuales, físicos y psicológicos a los que se exponen las mujeres por parte de jefes o jefas, ya que el trabajo doméstico remunerado, no solo se encuentra feminizado, sino que está todavía asociado a la servidumbre, lo cual hace que persistan prácticas arraigadas a dinámicas coloniales (Carcedo, Lexartza y Chaves Groh 2011; Hidalgo Xirinachs 2016; Sandoval García, Brenes Montoya y Paniagua Arguedas 2012).

Por último, si bien se ha estudiado en Costa Rica el trabajo doméstico no remunerado de mujeres migrantes, se requiere identificar que la necesidad de 
este trabajo en la meseta central es la punta de un iceberg de una crisis social en la organización del trabajo de los cuidados y del trabajo doméstico en el país, y que se extiende sobre todo en el Valle Central. Por lo tanto, se debe analizar el papel del mercado, el Estado y la familia para resolver esta tensión desde la corresponsabilidad social, puesto que actualmente se evidencia que, hasta ahora, la forma más barata y más expedita de resolver la tensión previamente explicada es a través de la contratación de mujeres migrantes, sobre todo nicaragüenses; y al mismo tiempo, implementando políticas maternalistas que siguen enfocando el cuidado como una responsabilidad exclusiva de las mujeres (Blofield y Martínez Franzoni 2014).

\section{Síntesis}

A lo largo del texto, se han expuesto los antecedentes y la evolución epistemológica feminista de un fenómeno que implica una tensión estructural, que ha sido invisibilizada por las teorías más androcéntricas. Estas últimas no habían reconocido el papel fundamental de la división sexual del trabajo o de la reproducción social en su faceta de labor doméstica, trabajo doméstico o trabajo de los cuidados, que se ha efectuado dentro de los hogares por tantos siglos y que ha sido crucial para el sostenimiento y la reproducción del sistema y de sus sociedades.

También se ha confirmado que esta esfera no reconocida dentro de la lógica pública de los Estados contiene un carácter feminizado; que esta es la razón principal de su carente valor social y económico; y, que esta privación del valor de estos trabajos es favorable al sostenimiento del mismo sistema.

De esta forma de organización de la vida en las sociedades capitalistas, racistas y patriarcales, devienen las brechas económicas de género, en las cuales se demostró, con datos de la CEPAL, que, por ejemplo, son las mujeres las más pobres y las más dependientes económicamente en toda la región latinoamericana. Asimismo, este tipo de organización social y económica se encuentra afianzada en las características y en los valores que se han arraigado culturalmente al género y que esta dicotomía genérica promueve el amor materno, en térmios del desarrollo de los valores asociados al sacrificio y a la sumisión, para que sean considerados como condiciones positivas para las mujeres y proclamados como beneficiosos para el mismo sistema económico.

El sistema cultural coadyuva a la reproducción de esta forma de trabajo que se realiza de manera invisible y gratuita, y que es beneficiosa para la sociedad y para el sistema económico, pero no para las mujeres que trabajan sin reconocimientos dentro de la esfera pública. Y que, además, son ellas quienes siguen asumiendo las dobles y las triples jornadas de trabajo; y, nuevamente, de manera invisible, con consecuencias para la salud integral y su bienestar. 
Los datos antes expuestos evidencian que la actual organización social del trabajo de los cuidados, en los ámbitos nacional y transnacional, es conferida en nivel jurídico y social a las mujeres; pero, sobre todo, a las mujeres empobrecidas, racializadas y migrantes, para que sean estos cuerpos precarizados en términos de derechos, de remuneración económica y de salud, quienes asuman mayoritariamente el sostenimiento de la vida de las sociedades dentro del sistema capitalista, patriarcal y blanco-centrado.

Así pues, desde el feminismo comunitario (Cabnal 2010; Cumes 2012), se afirma que las sociedades se sostienen a través de la opresión de las mentes y de los cuerpos de las mujeres y que debemos cuestionar esta posición históricamente situada de víctima sumisa, con el fin de rescatar los cuerpos femeninos como un espacio de resistencia y de autodeterminación (Cabnal 2010). Consiste en tomar conciencia y en reflexionar cuál ha sido la posición de las distintas mujeres en la sociedad y el uso que se le ha dado a estos cuerpos, para recuperar que el supuesto feminista de lo personal es político (Millett 1995), en donde se reivindica lo imprescindible de lo que acontece en el espacio privado de los hogares, incluido el trabajo de las mujeres. Y así, rescatar estos trabajos, que han sido conferidos sobre todo a las mujeres más precarizadas, cuyo valor es fundamental en la organización y en la reproducción de la vida; $y$, por lo tanto, es fundamental cambiar su concepción y valor, para resignificarlos dentro de la organización social, cultural y económica de nuestras sociedades.

\section{Conclusiones y recomendaciones}

Costa Rica, al igual que muchos países en América del Sur, se enfrenta a una crisis en la OSC producto de la tensión entre la división sexual del trabajo, la incorporación de la mujer al mercado laboral y los pocos mecanismos o estrategias de la política social del Estado por reorganizar, de manera colectiva, estos trabajos dentro de los hogares.

Ese tipo de organización social ha sido asumida históricamente por las mujeres, producto de las construcciones sociales y culturales sobre el género, las cuales han normalizado el papel de la mujer como la persona obligada a realizar el trabajo de los cuidados y el trabajo doméstico dentro de las familias.

En ese sentido, Costa Rica ha apostado por dar algunos pasos en el avance de políticas públicas de desfamiliarización, como la REDCUDI (Asamblea Legislativa de Costa Rica 2014), o la Red de Atención Progresiva para el Cuidado Integral de las Personas Adultas Mayores en Costa Rica (Presidencia de la República de Costa Rica 2012). Sin embargo, estas iniciativas disponen de poco financiamiento y pocos esfuerzos para constituirlas de manera universal; además, existe una falta de interés por poner esta crisis en el centro de la discusión social y económica. 
Así pues, se siguen inscribiendo paralelamente prácticas maternalistas que reproducen de nuevo los estereotipos de género; por ejemplo, la contratación de mujeres, sobre todo las migrantes, para que realicen el trabajo doméstico remunerado y los cuidados a lo interno de los hogares costarricenses, como la solución inmediata a esta crisis, y legitimada en la actual ley de migración.

De esta forma, la noción de la familia nuclear se encuentra presente en el desarrollo de todas las estrategias para conciliar los cuidados, lo cual legitima a este tipo de estructura familiar y estigmatiza a las demás. Esto trae consecuencias importantes para las familias monoparentales con jefatura femenina.

Se pudo constatar que, en Costa Rica, se ha venido generando una transformación paulatina de la estructura familiar, en la cual la familia nuclear heterosexual con hombre proveedor disminuye con el tiempo. Por lo tanto, este modelo familiar no es representativo de todas las estructuras familiares de la sociedad, y al mismo tiempo, tal modelo institucionalizado repercute negativamente en los hogares de mujeres jefas de hogar sin pareja heterosexual, sean migrantes o costarricenses. La invisibilización de su propia realidad tiene congruencia con las altas cifras de hogares MPJF en los índices de pobreza y de pobreza extrema.

El modelo de la familia nuclear arraigado en la normativa y en las políticas perpetúa las desigualdades socioeconómicas para las familias de hogares monoparentales con jefatura femenina. Estas políticas disminuyen las posibilidades de mejorar la situación de dichos hogares, puesto que no existen medidas explícitas para conciliar el trabajo de los cuidados del propio hogar y el trabajo en el mercado. Esta tensión perpetúa en las mujeres pobres las dobles y triples jornadas laborales, la informalidad y la flexibilidad laboral, la desprotección de la seguridad social y la carencia de cuidados para sus propias familias.

Si se enfatiza específicamente en analizar la realidad de las mujeres nicaragüenses jefas de hogar que se emplean, por lo general, como trabajadoras domésticas remuneradas, se puede identificar que son ellas quienes se encuentran en múltiples situaciones de explotación y de precarización, mucho mayores que otras poblaciones, y que, además, viven la discriminación de manera particular.

A pesar de que el país ha avanzado en el ámbito legislativo con la promoción de la Ley de Trabajo Doméstico Remunerado (Asamblea Legislativa de Costa Rica 2009); con la Ley de Contabilización del Aporte del Trabajo Doméstico no Remunerado (Asamblea Legislativa de Costa Rica 2015); con las encuestas de uso del tiempo (INAMU, INEC 2018; Sandoval et al. 2012); y con la firma del convenio 189 y 156 de la OIT sobre el trabajo decente para las trabajadoras y los trabajadores domésticos, y para la corresponsabilidad social en el cuido, ratificadas en el año 2014 y 2019 respectivamente, todavía se reproducen situaciones de informalidad laboral e irrespeto a los derechos laborales de las personas trabajadoras domésticas, así como de las mujeres 
que viven las dobles y las triples jornadas de trabajo, con repercusiones para su salud integral.

Así pues, sí desde la política social del Estado costarricense se incorporaran las nociones sobre cuidado y maternidad en congruencia con las realidades de mujeres jefas de hogar que integran los índices más altos de hogares pobres, se podría estar apuntando a solventar las necesidades de las personas más empobrecidas del país, porque se implementarían estrategias de corresponsabilidad social más anuentes con las realidades cambiantes y las transformaciones familiares que requiere la sociedad.

En este orden de ideas, es importante dirigir acciones específicas para dinamizar y para fortalecer el trabajo de los cuidados como un trabajo de valía con un contenido político y económico más favorable. Por ejemplo, se pueden encaminar proyectos para la promoción de educación abierta a través de técnicos especializados en la provisión de cuidados, con el objetivo de que estas mujeres reciban un reconocimiento social por el trabajo que realizan. También, se debería ampliar la cobertura de la REDCUDI (Asamblea Legislativa de Costa Rica 2014) y de la Red de Atención Progresiva para el Cuidado Integral de las Personas Adultas Mayores (Presidencia de la República de Costa Rica 2012) para niños, niñas y adultos mayores de todas las condiciones sociales, así como para personas con discapacidad, a partir del involucramiento y de la participación social y económica de toda la sociedad, de la población residente proveniente de países de renta alta y de las empresas nacionales y extranjeras que se emplazan en el país.

Como sugerencia, es importante dirigir normativas y acciones específicas para que todos los sectores de la sociedad costarricense participen de manera colectiva. De esta forma, se estaría apostando por nuevos paradigmas de desarrollo los cuales pongan la atención en el cuidado y en el bienestar de las personas que más los necesitan.

La visibilización y atención particular de las realidades y necesidades de estas poblaciones de mujeres es el camino para desarrollar acciones específicas que conduzcan a incrementar el bienestar de las familias que integran las cifras de pobreza y pobreza extrema en el país. Asimismo, se estaría ofreciendo cuidados y atención de calidad para todas las familias, lo cual sería el primer paso para que la sociedad se levante en conjunto. Además, se estaría activando y dinamizando la economía a través de un modelo en el cual las familias que más recursos necesitan se incluyan a través de apoyos financiados de manera colectiva, como podría ser el caso de la REDCUDI.

De esa forma, se podría redefinir las nociones tradicionales sobre la transferencia de cuidados exclusivo de las mujeres, para originar mecanismos más igualitarios y distributivos a fin de mejorar sus condiciones de vida y las de sus familias, así como la atención en el cuidado de las familias costarricenses; y, por último, para transformar las construcciones culturales y sociales asociadas al género femenino y al régimen familista 
instaurado en el país. Asimismo, el Estado podría disminuir las cifras de pobreza y pobreza extrema.

En resumen, se podría empezar a transformar el valor social de los trabajos que históricamente han sido feminizados si se cargan de valía social y se incorpora a la población masculina. Además, generaría fuentes de ingreso a las poblaciones que más lo necesitan y se reconocería, desde la esfera pública, que el trabajo doméstico y el trabajo de los cuidados es necesario para construir un sistema que ponga la vida en el centro. Al mismo tiempo, se recuperaría el espacio de participación para todas las mujeres dentro de la esfera pública.

\section{Bibliografía}

Alber, Jens. 1995. «A Framework for the Comparative Study of Social Service 's». Journal of European Social Policy 5 (2): 131-49. doi: https://doi.org/ 10.1177/095892879500500204

Anderson, Brigit. 2000. Doing the Dirty Work: The Global Politics of Domestic Labour. London: Sed Books.

Anttonen, Annelli, y Jorma Sipillä. 1996. «European Social Care Services: Is it Possible to Identify Models». Journal of European Social Policy 5 (2): 87-100. Doi: https://doi.org/10.1177/095892879600600201

Ariza, Marina, y Orlandina de Oliviera. 2004. «Familias, pobreza y necesidades de políticas públicas en México y Centroamérica». En Cambio de las familias en el marco de las transformaciones globales: necesidad de políticas públicas eficaces. Santiago: CEPAL. Acceso el 11 junio de 2016. https://www.cepal.org/es/publicaciones/6773-cambiofamilias-marco-transformaciones-globales-necesidad-politicas-publicas

Arriagada, Irma, y Rosalba Todaro. 2012. «Cadenas globales de cuidados: EI papel de las migrantes peruanas en la provisión de cuidados en Chile». Santo Domingo: ONU Mujeres. Acceso el 24 de octubre 2017. https://www.researchgate.net/publication/298592925_Arriagada_Irma_y Todaro_Rosalba_2012_Cadenas_globales_de_Cuidados_El_papel_d e las_migrantes_peruanas_en_la_provision_de_cuidados en_Chile

Asamblea Legislativa de Costa Rica. 2009. Ley General de Migración y Extranjería. Vol. 8764. Acceso 3 de diciembre 2018. http://www.pgrweb.go.cr/scij/Busqueda/Normativa/Normas/nrm texto_c ompleto.aspx? param1 $=$ NRTC $\&$ nValor1 $=1 \&$ nValor2=66139\&nValor3=0\&strTipM=TC - 2014. Red Nacional de Cuido y Desarrollo Infantil. Acceso 29 de enero 2018. http://www.pgrweb.go.cr/scij/Busqueda/Normativa/Normas/ nrm texto_completo.aspx? 
param1=NRTC\&nValor1=1\&nValor2=77044\&nValor3=96409\&strTipM=T $\underline{\mathrm{C}}$

2015. Contabilización del Aporte del Trabajo Doméstico no Remunerado en Costa Rica. Acceso 17 mayo 2018. http://www.pgrweb.go.cr/scij/Busqueda/Normativa/Normas/nrm texto_c ompleto.aspx?

param1=NRTC\&nValor1=1\&nValor2=80557\&nValor3=102244\&strTipM= $\underline{\mathrm{TC}}$

Banco Central de Costa Rica. 2019. «Cuenta satélite. Trabajo doméstico no remunerado en Costa Rica, año 2017». Presentado en Simposio Internacional de Estudios sobre uso del tiempo. Aportes para la Igualdad entre mujeres y hombres, Universidad Nacional. Acceso 20 octubre

2019. https://activos.bccr.fi.cr/sitios/bccr/indicadoreseconomicos/CuentaSatelit eTrabajoDomesticoNoRemunerado/Metodologia_CSTDNR_2017.pdf

Blofield, Merike, y Juliana Martínez Franzoni. 2014. «Trabajo, familia y cambios en la política pública en América Latina: equidad, maternalismo y corresponsabilidad». Revista CEPAL 114: 107-25. $\begin{array}{llll}\text { Acceso } & 11 & \text { de } & \text { septiembre }\end{array}$ https://repositorio.cepal.org/handle/11362/37439

Borderías, Cristina, Cristina Carrasco y Teresa Torns. 2011. «Introducción. El trabajo de cuidados: antecedentes históricos y debates actuales». En El trabajo de los cuidados. Historia, teoría y políticas. Madrid: Los libros de la Catarata.

Cabnal, Lorena. 2010. «Acercamiento a la construcción del pensamiento epistémico de las mujeres indígenas comunitarias de Abya Yala». En Feminismos diversos: el feminismo comunitario. España: ACSUR-Las Segovias.

Calquín, Claudia. 2014. «Inmigración y transnacionalismo en la construcción de nuevas maternidades latinoamericanas» Cuadernos del pensamiento latinoamericano, 18: 123-41. Acceso el 18 de septiembre. http://www.cuadernoscepla.cl/web/wp-content/uploads/ClaudiaCalquin.pdf

Carballo Meza, Melida, y Migdalia Castro Quintanilla. 2011. Situación y perspectiva de las mujeres migrantes nicaragüenses en los cantones de Liberia y La Cruz. San José: INAMU.

Carcedo, Ana, Lexartza Lexartza, y María José Chaves Groh. 2011. Cadenas globales de cuidados: el papel de las migrantes nicaragüenses en la provisión de cuidados en Costa Rica. Santo Domingo: ONU.

Castro, Carlos. 2007. «Dimensión de la inmigración nicaragüense en Costa Rica.» En El mito roto. Inmigración y emigración en Costa Rica. San José: Editorial UCR. 
CEPAL. 2017. «Índice de feminidad en hogares pobres». Observatorio. Observatorio de Igualdad de Género de América Latina y el Caribe (blog). 2017. Acceso 23 de junio 2020. https://oig.cepal.org/es/indicadores/indice-feminidad-hogares-pobres.

Chaves Groh, María José. 2013. Derecho a tener derechos. Monitoreo de la aplicación de la Ley General de Migración y Extranjería (N. $\left.{ }^{\circ} 8764\right)$ y el Acceso de las Mujeres a un Estatus Migratorio Regular. 1. ${ }^{a}$ ed. San José: CEFEMINA.

Chaves Jiménez, Rocío y Ana Lucía Fernández Fernández. 2016. «Crítica feminista al concepto "nini" (ni trabaja ni estudia)». Revista Rupturas 6 (2): 163-95. Acceso 23 de octubre 2017. file:///Users/analuciafernandez/Downloads/1476-Texto\%20del\%20art \%C3\%ADculo-3389-1-10-20160628.pdf

Cobo Bedia, Rosa, Rosario Ortega Serrano, Begoña Leyra Fatou y Marta Aparacio García. 2009. Cuadernos de género: políticas y acciones de género: materiales de formación. Madrid: Instituto Computense de Estudios Internacionales D.L.

Código de trabajo de Costa Rica. 1943. Código de Trabajo de Costa Rica. http://www.tse.go.cr/pdf/normativa/codigodetrabajo.pdf.

Consejo Nacional de Migración. 2013. Política migratoria integral para Costa Rica. San José: OIT. San José: OIT.

Constable, Nicole. 1997. Maid to Order in Hong Kong. An Ethnography of Filipino Domestic Worker. Ithaca: Cornell University Press.

Cumes, Aura Estela. 2012. «Mujeres indígenas, patriarcado y colonialismo: un desafío a la segregación comprensiva de las formas de dominio». En Anuario Hojas de Warmi. Universidad de Murcia, 17: 1-16.

DAES. 2013. La migración mundial en cifras. New York: Naciones Unidas. Acceso 10 de agosto. https://www.oecd.org/els/mig/SPANISH.pdf

Dalla Costa, Mariarosa, y Selma James. 1972. Women and the subversion of the community. Frome y Londres: Butler and Tanner Ltd.

Daly, Mary, y Jane Lewis. 2011. «El concepto de "social care" y el análisis de los Estados de bienestar contemporáneos». En El trabajo de cuidados. Historia, teoría y políticas, 225-51. Madrid: Los libros de la Catarata.

Ehrenreich, Bárbara y Arlie Hochschild. 2002. Global Woman. Nannies, Maids, and Sex Workers in the New Economy. New York: Henry Holt and Company, LLC.

Engels, Friedrich. (1884) 1966. El origen de la familia, la propiedad privada y el Estado. Traducido por Juan Fajardo. 4. ${ }^{a}$ ed. Moscú: Editorial Progreso.

Esping-Andersen, Gösta. 1990. The Three Worlds of Welfare Capitalism. Princeton: Princeton University Press. 
Estado de la Nación. 2002. «Aportes para el análisis de las brechas de equidad entre los géneros. Insumos para su medición». Estado de la Nación. Acceso 10 de agosto 2020. http://sistemas.inec.cr:8080/redinec/indicadores/Genero/DocumentosRe ferenciaGenero/archivos/ AportesAnalisisBrechasDeEquidadEntreGeneros.pdf

Evers, Adalbert y Ivan Svetlik, eds. 1993. Balancing Pluralism. New Welfare Mixes in Care for the Eldery. Aldershot: Avebury.

Federici, Silvia. 2010. Calibán y la Bruja. Mujeres, cuerpo y acumulación originaria. Traducido por Verónica Hendel y Leopoldo Sebastián Touza. Madrid: Traficantes de sueños.

Finch, Janete y Dulcie Groves. 1993. Labour of Love: Women, Work and Caring. London: Routledge and Kegan Paul.

Folbre, Nancy. 1995. "“Holding hands ar midnight": The paradox of caring labor». Feminist Economics 1 (1): 73-92. Doi: 10.1080/714042215.

Gatica López, Gustavo. 2013. Perspectivas socioeconómicas de la población migrante en Costa Rica (N. ${ }^{\circ}$ Investigación Final). San José: Estado de la Nación.

Gonzálvez Torralbo, Herminia. 2013. «Los cuidados en el centro de la migración. La organización social de los cuidados transnacionales desde un enfoque de género». Migraciones 33: 127-53. Acceso 10 agosto 2020. http://www.mujeresyfronteras.com/wp-content/uploads/2019/07/Gonzalv ez-2013_Los-cuidados-en-el-centro-de-la-migracion.pdf

Graham, Hilary. 1991. «The concept of Caring in Feminist Research: The case of domestic service». Sociology 25 (1): 61-78. Doi: https://doi.org/ 10.1177/0038038591025001004

Guerrero Segura, Efraín Antonio, Freddy Mauricio Montero Mora, Sergio Muñoz Chacón, y Onías García Pérez. 2012. Migración e integración en Costa Rica: Informe nacional 2012. San José: Dirección General de Migración y Extranjera República de Costa Rica.

Guitiérrez-Rodríguez, Encarnación. 2010. Migration, Domestic Work and Affect: A Decolonial Approach on Value and the Feminization of Labor. Routledge. https://books.google.de/books?id=3JhVFi4UbW8C.

Hernández Cordero, Ana Lucía. 2016. «En España se necesitan mujeres para trabajar. Guatemaltecas inmigrantes y las cadenas globales de cuidado». En Migraciones en América Central. Políticas, territorios y actores, editado por Carlos Sandoval García, 47-65. San José: Editorial UCR.

Herrera Mosquera, Gioconda. 2011. "Cuidados globalizados y desigualdad social. Reflexiones sobre la feminización de la migración andina». Revista Nueva Sociedad 233: 87-97. Acceso 28 de octubre 2017. 
https://nuso.org/articulo/cuidados-globalizados-y-desigualdad-socialreflexiones-sobre-la-feminizacion-de-la-poblacion-andina/

- 2012. «Repensar el cuidado a través de la migración internacional: mercado laboral, Estado y familias transnacionales en Ecuador». Cuadernos de Relaciones Laborales 30 (1): 139-59. Doi: https://doi.org/ 10.5209/rev_CRLA.2012.v30.n1.39118

. 2013. «Lejos de tus pupilas» Familias transnacionales, cuidados y desigualdad social en Ecuador. Quito. FLACSO Ecuador-ONU Mujeres.

Hidalgo Xirinachs, Roxana. 2016. Mujeres de las fronteras. Subjetividad, migración y trabajo doméstico. 1. ${ }^{\mathrm{a}}$ ed. San José: Editorial UCR.

Himmelweit, Susan. 1999. "Caring Labor». The Annals of the Amercian Academy of Political and Social Science 561 (Emotional Labor in the Service Economy): 27-38. Acceso 19 de octubre 2017. http://www.jstor.org/stable/1049279.

. 2011. "Capítulo 5. El descubrimiento del "trabajo no remunerado": consecuencias sociales de la expansión del término "trabajo"». En El trabajo de los cuidados. Historia, teoría y políticas, 199-224. Madrid: Los libros de la Catarata.

Hochschild, Arlie Russell. 2003. The Managed Heart. Commercialization of Human Feeling. Edición del 20 aniversario. California: University of California Press. Doi: https://doi.org/10.5465/amr.1985.4278667

Hondagneu-Sotelo, Pierrette. 2001. «Doméstica: Immigrant Workers Cleaning and Caring in the Shadows of Affluence». University of California Press. Doi: https://doi.org/10.1086/382007

INAMU. 2008. Estimaciones y proyecciones de población por sexo y edad (cifras actualizadas) 1950-2050. Estudio sobre las percepciones sociales sobre el cuido. San José: INAMU-IDESPO.

INAMU. 2015. Segundo Estado de los Derechos Humanos de las Mujeres en Costa Rica. 1. ${ }^{a}$ ed. San José: INAMU.

INAMU, INEC. 2018. Encuesta Nacional de Uso del tiempo 2017. Resultados generales. San José: INEC. Acceso 17 mayo 2017. https://www.inec.cr/ sites/default/files/documetos-biblioteca-virtual/reenut2017.pdf

INEC. 2011a. «X Censo Nacional de Población y VI de Vivienda 2011. Presentación de Resultados Generales». San José: INEC.

. 2011b. «Prevalecen desigualdades por sexo en el uso del tiempo». INEC, 10 diciembre 2011. Acceso 10 de agosto 2020. https://www.inec.cr/noticia/prevalecen-desigualdades-por-sexo-en-eluso-del-tiempo.

. 2012. X Censo Nacional de Población y VI de Vivienda 2011. Resultados generales. San José: Instituto Nacional de Estadísticas y 
Censos. $\quad$ Acceso $11 \quad$ agosto 2017. https://www.cipacdh.org/pdf/Resultados_Generales_Censo_2011.pdf

. 2017a. «Cuadro. Costa Rica: Principales características de los hogares y de las personas. Por nivel de pobreza. Según zona Julio 2017». En Encuesta Nacional de Hogares 2017. San José: INEC. Acceso 23 de junio 2020. https://www.inec.cr/

—. 2017b. «Gráfico. PEA femenina migrante en Costa Rica. año 2011.» Consulta al INEC. San José: INEC. Acceso 30 de mayo 2017. https://www.inec.cr/

Jelin, Elizabeth. 2014. «Desigualdades de clase, género y etnicidad/raza. Realidades históricas, aproximaciones analíticas». desiguALdades.net International Research Network on Interdependent Inequalities in Latin America, Working Paper Series, 73: 33.

Knijn, Trudie, y Monique Kremer. 1997. «Gender and the Caring Dimension of Welfare States: Toward inclusive Citizenship». Social Politics 4 (3): 328-61.

La Defensoría de los Habitantes. 2017. «Informe Anual de labores 20162017». San José: La Defensoría de los Habitantes de Costa Rica.

Larguía, Isabel y John Dumoulin. 1976. Hacia una ciencia de la liberación de la mujer. Barcelona: Anagrama.

Lerussi, Romina Carla. 2008. «Trabajadoras domésticas nicaragüenses en Costa Rica. En las encrucijadas de un debate feminista». Madrid: Magister en Género y Desarrollo, Instituto Complutense de Estudios Internacional (ICEI). Universidad Complutense se Madrid.

Lexartza Artza, Larraitz. 2010. Costa Rica. Trabajo decente y corresponsabilidad en el cuido: Restos en el camino hacia la igualdad. $1^{\text {a }}$ ed. San José: OIT. Acceso 22 de junio 2020. https://www.ilo.org/wcmsp5/groups/public/---americas/---ro-lima/---srosan_jose/documents/publication/wcms 179040.pdf

Martínez Franzoni, Juliana. 2008. ¿Arañando el bienestar? Trabajo remunerado, protección social y familias en America Central. Buenos Aires: CLACSO. Acceso 25 octubre 2017. http://biblioteca.clacso.edu.ar/clacso/clacso-crop/20100620023228/ bienestar.pdf

Martínez Franzoni, Juliana y Koen Voorend. 2009. Sistemas de patriarcado y regímenes de bienestar en América Latina ¿Una cosa lleva a la otra? 1. ${ }^{a}$ ed. Documento de trabajo $n^{\circ} 37$. Madrid: Fundación CarolinaCeALCl. Acceso 25 de octubre 2017. https://www.academia.edu/2999184/2009 Sistemas_de_patriarcado_y_ reg\%C3\%ADmenes de bienestar_en_Am

\%C3\%A9rica_Latina_Una_cosa_lleva_a_la_otra_Con_Koen_Voorend_ Libro_serie_Documento_27_Madrid_Fundaci\%C3\%B3n_Carolina 
Millett, Kate. 1995. Política sexual. A. Moreno, Trad. Madrid: Ediciones Cátedra.

Molyneux, Maxime. 1979. «Beyond the Domestic Labour Debate». New Left Review 116: 357-73. Acceso 23 de octubre 2017.

Morales Gamboa, Abelardo, ed. 2011. Migración de relevo, territorios locales e integración regional en Centroamérica. San José: FLACSO. Acceso 14 marzo 2018. http://biblioteca.clacso.edu.ar/Costa_Rica/flacso-cr/20170704045457/ pdf_196.pdf.

Morales, Natalia e Isabel Román. 2013. «Informe Final. Principales transformaciones en el perfil de los hogares con jefatura femenina en Costa Rica en los últimos veinticinco años (1987-2013)». En Vigésimo informe Estado de la nación en desarrollo humano sostenible 2013. San José: Estado de la Nación. Acceso 11 de agosto 2017. http://repositorio.conare.ac.cr/handle/20.500.12337/351

Naciones Unidas. 2017. Empleo en América Latina y el Caribe (Páginas selectas de la CEPAL). Santiago: 446. Acceso 23 de junio 2020. https:// www.cepal.org/es/publicaciones/42488-empleo-america-latina-caribetextos-seleccionados-2006-2017

OIT. 2010. Costa Rica. Trabajo decente y corresponsabilidad social en el cuido: retos en el camino hacia la igualdad. San José: OIT. Acceso 11 de agosto 2017. https://www.ilo.org/wcmsp5/groups/public/--americas/---ro-lima/---sro-san_jose/documents/publication/ wcms 179040.pdf

Parreñas, Rachel. 2001. Servants of Globalization: Women, Migration and Domestic Work. California: Standford University Press.

Pedone, Claudia. 2008. «Varones aventureros vs. Madres que abandonan: reconstrucción de las relaciones familiares a partir de la migración». REMHU. Revista Insterdisciplinar da Mobilidade Humana XVI (30): 4564. Acceso $28 \quad$ septiembre 2017. https://www.redalyc.org/pdf/4070/407042007004.pdf

Pérez Orozco, Amaia. 2006a. «Amenaza tormenta: La crisis de los cuidados y la reorganización del sistema económico». Revista de Economía Crítica 5: 7-37. Acceso 25 de octubre. http://observatoridesc.org/sites/default/files/1_amenaza_tormenta.pdf . 2006b. Perspectivas feministas en torno a la economía: El caso de los cuidados. 1. ${ }^{\mathrm{a}}$ ed. Madrid: Consejo Económico y Social.

. 2007. Cadenas globales de cuidado. Documento de trabajo $n^{\circ} 2$. Santo Domingo: INSTRAW. Acceso 30 octubre 2017. http://mueveteporlaigualdad.org/publicaciones/cadenasglobalesdecuida do_orozco.pdf 
2009. Miradas globales a la organización social de los cuidados en tiempos de crisis II: ¿Qué retos políticos debemos afrontar? Santo Domingo: INSTRAW, AECID.

Pérez Orozco, Amaia, y Silvia López Gil. 2011. Desigualdad a flor de piel: cadenas globales de cuidados. Concreciones en el empleo de hogar y políticas públicas. Madrid: ONU Mujeres. Acceso 2 de octubre 2017. https://www.flacsoandes.edu.ec/sites/default/files/agora/files/127169295 8.amaia_perez_orozco_working_paper_6_espanol.pdf

Pérez Sáinz, Juan Pablo, y Minor Mora Salas. 2007. La persistencia de la miseria en Centroamérica: una mirada desde la exclusión social. San José: FLACSO.

Presidencia de la República de Costa Rica. 2012. «Red de atención progresiva para el cuido integral de las personas adultas mayores en Costa Rica. II versión: revisada y ampliada». San José. Acceso 16 mayo 2018. https://www.conapam.go.cr/mantenimiento/Red_Cuido.pdf

Programa Estado de la Nación. 2017. «Estado de la Nación». 23. San José: Programa Estado de la Nación.

Quiroga Díaz, Natalia. 2011. «Economía del cuidado. Reflexiones para un feminismo decolonial». Revista Casa de la Mujer 20 (2): 97-116. Acceso 11 agosto 2017. https://www.bibliotecafragmentada.org/wpcontent/uploads/2015/05/Econom\%c3\%ada-del-cuidado.-Reflexionespara-un-feminismo-decolonial.pdf

Rodríguez Enríquez, C. 2007. «Empleo femenino, economía del cuidados y políticas públicas. Algunas consideraciones desde la experiencia argentina». En Entre familia y trabajo. Relaciones, conflictos y políticas de género en Europa y América Latina, 177-202. Rosario: Editorial Homo Sapiens.

Román, Isabel y Natalia Morales. 2010. Demanda potencial de cuido infantil según estructura de los hogares: el caso de Costa Rica. San José: INAMU-Estado de la Nación. Acceso 6 de noviembre 2017. http://biblioteca.icap.ac.cr/BLIVI/COLECCION_UNPAN/BOL_OCTUBR E_2013_67/PROG_ESTADO_NACION/2010/cuido_infantil_2010.pdf

Saffioti, Heleieth. 1969. La sujeción de la mujer. Sao Pablo: Quatro Altes Universitaria.

Sánchez Arias, Claribel. 2013. «Procesos de precarización de las relaciones socio laborales del régimen de zona franca: un estudio de caso de las mujeres trabajadoras de maquila industrial en Heredia y Puntarenas 2009-2010». Sociología, Ciudad Universitaria Rodrigo Facio: Universidad de Costa Rica.

Sanchis, Norma, y Corina Rodríguez Enríquez. 2010. Cadenas globales de cuidados: El papel de las migrantes paraguayas en la provisión de cuidados en Argentina. Santo Domingo: ONU Mujeres. Acceso 25 de 
octubre 2017.

https://trainingcentre.unwomen.org/participacionpolitica/wp-content/ uploads/2018/01/009_Cadenas_Globales_Cuidados.pdf

Sandoval García, Carlos. 2015. No más muros. Exclusión y migración forzada en Centroamérica. 1. ${ }^{a}$ ed. San José: Editorial UCR.

Sandoval García, Carlos, Mónica Brenes Montoya, y Laura Paniagua Arguedas. 2012. La dignidad vale mucho. Mujeres nicaragüenses forjan derechos en Costa Rica. 2012. San José: Editorial Universidad de Costa Rica.

Sandoval Carvajal, Irma, Lidia González Vega, Guiselle Rodríguez Villalobos, y Laura Guzmán Stein. 2012. Uso del tiempo en la Gran Área Metropolitana 2011: una mirada cuantitativa del trabajo invisible de las mujeres. San José: Instituto Nacional de las Mujeres. San José: Instituto Nacional de las Mujeres.

Sassen, Saskia. 2003. Contra geografías de la globalización. Género y ciudadanía en los circuitos transfronterizos. Madrid: Traficantes de sueños, Queimada Gráficas.

Silvey, Rachel. 2004. "Transnational Domestication: Indonesian Domestic Workers in Saoudi Arabia». Political Geography 23 (3): 245-64. Acceso 10 de agosto 2020. file:///Users/analuciafernandez/Downloads/Transnational_Migration_and the Gender_P.pdf

Thomas, Carol. 1993. «De-constructing Concepts of Care». Sociology 27 (4): 649-69. Doi: https://doi.org/10.1177/0038038593027004006

Ungerson, Clare. 1997. "Social Politics and the Commodification of Care». Social Politics 4 (3): 362-82. doi:10.1093/sp/4.3.362.

Uría, Paloma, Empar Pineda, y Montserrat Oliván. 1985. Polémicas feministas (trabajo doméstico ¿valor, plusvalía?). Madrid: Editorial Revolución.

Vargas, Ana Jimena. 2017. «Informe Estado de la Nación en desarrollo humano sostenible 2017. La Red Nacional de cuido y desarrollo infantil (REDCUDI): características de los proveedores de servicio y sus desafíos». Estado de la Nación. Acceso 29 de enero 2018. file:///Users/ analuciafernandez/Downloads/1049.\%20La\%20Red\%20Nacional \%20de\%20Cuido\%20y\%20Desarrollo\%20Infantil $\% 20$ (REDCUDI)_Caracter\%C3\%ADsticas\%20de\%20los \%20proveedores $\% 20$ de $\% 20$ servicio $\% 20 y \% 20$ sus $\% 20$ desaf \%C3\%ADos_Estado\%20de\%20la\%20Naci\%C3\%B3n_Cap \%C3\%ADtulo\%20Equidad $\% 20$ e $\% 20$ integraci $\%$ C3\%B3n\%20social.pdf

Walby, Sylvia. 1997. Gender Transformations. Londres y Nueva York: Routledge. Doi: https://doi.org/10.4324/9780203431153 
Wareness, Kari. 1984. Caring as Women's Work in the Welfare State. Oslo: Universitetsforlaget.

Yeates, Nicola. 2005. "Global care chains: a critical introduction». Global migration perspectives 44: 1-20.Acceso 30 octubre 2017. https://www.refworld.org/docid/435f85a84.html 